\title{
In vitro reconstitution of functional yeast U2 snRNPs
}

\author{
David S. McPheeters, Patrizia Fabrizio, and John Abelson ${ }^{1}$ \\ Division of Biology, California Institute of Technology, Pasadena, California 91125 USA
}

\begin{abstract}
A system for the functional reconstitution of yeast U2 snRNPs using synthetic U2 RNAs is described. We use oligonucleotide-directed RNase $H$ cleavage to specifically deplete yeast extracts of their endogenous full-length U2 snRNA and consequently inactivate pre-mRNA splicing activity. The subsequent addition of synthetic yeast U2 RNAs, derived by in vitro transcription (T7U2 RNAs), to these oligonucleotide-treated extracts efficiently reconstitutes their ability to splice pre-mRNA. The use of deletion derivatives of the T7U2 RNA has demonstrated that the region downstream from the conserved Sm-binding site sequence in the yeast U2 RNA is not absolutely required for pre-mRNA splicing activity in vitro. Furthermore, we found that both human and rat U2 RNAs can function in yeast extracts. We also show that point mutations in the yeast U2 RNA can be analyzed using the in vitro reconstitution system. Allele-specific suppression of mutations in pre-mRNA branch site sequence is observed when the appropriate compensatory mutations in the branch site recognition region of the T7U2 RNA are introduced. Finally, we present a model for the interaction of the U2 and U6 snRNAs during pre-mRNA splicing.
\end{abstract}

[Key Words: U2 snRNA; U6 snRNA; snRNP; RNA splicing; reconstitution]

Received August 24, 1989; revised version accepted October 13, 1989.

The removal of introns from nuclear pre-mRNAs requires the U1, U2, U5, and U4/U6 small ribonucleoprotein particles (snRNPs), as well as multiple protein factors, assembled into a large complex termed the spliceosome (for review, see Steitz et al. 1988). Through biochemical and genetic studies, it is now well established that the U2 snRNP interacts with the branch site sequence, and that the Ul snRNP interacts with the 5' splice site (for review, see Steitz et al. 1988). Other biochemical studies have suggested that the U5 snRNP interacts with the $3^{\prime}$ splice site (Chabot et al. 1985). The function of the U4/U6 snRNP in pre-mRNA splicing is unknown, although it has been suggested that U6 functions intimately in the catalysis of pre-mRNA splicing (Brow and Guthrie 1989; see also Discussion). Mammalian U1, U2, and U5 snRNPs each contain a single small nuclear RNA (snRNA) molecule associated with seven core $\mathrm{Sm}$ proteins, as well as proteins specific to each individual snRNP. The mammalian U4/U6 snRNP also contains these same core Sm proteins, but consists of two different snRNAs associated in a single snRNP (for review, see Lührmann 1988). Portions of the primary and secondary structures of the U1, U2, U4, U5, and U6 snRNAs are highly conserved in organisms ranging from yeast to mammals (for review, see Guthrie and Patterson 1988). This high degree of conservation, as well as fundamental similarities in the mechanisms of nuclear premRNA splicing and the autocatalytic splicing of group II introns has led to the suggestion that the RNA moieties

${ }^{1}$ Corresponding author. of the snRNPs are directly responsible for the catalysis of nuclear pre-mRNA splicing (Kruger et al. 1982; Cech 1986).

The U2 snRNP was first implicated in branch site sequence recognition by nuclease protection assays that demonstrated that the mammalian U2 snRNP binds to a region within introns containing the branch site sequence (Black et al. 1985; Chabot and Steitz 1987). In the yeast Saccharomyces cerevisiae, the branch site sequence, UACUAAC, is highly conserved and branch formation occurs at the most $3^{\prime}$ adenosine within this sequence (Domdey et al. 1984; Langford et al. 1984; Rodriguez et al. 1984). Using an elegant in vivo suppression assay, Parker et al. (1987) demonstrated that the interaction between the yeast U2 snRNP and the highly conserved branch site sequence is mediated, at least in part, by the base-pairing of the branch site sequence in the pre-mRNA with the U2 snRNA.

Despite the unusually large size of the yeast U2 snRNA ( 1175 nucleotides) in comparison to its mammalian counterparts ( $\sim 188$ nucleotides), the yeast U2 snRNA can be folded into a structure (Fig. 1; Guthrie and Patterson 1988; Ares and Igel 1989) that resembles the structure originally proposed for metazoan U2 snRNAs by Keller and Noon (1985). U2 snRNAs in general can be divided into four conserved domains (Fig. 1; Guthrie and Patterson 1988; Ares and Igel 1989|. The branchpoint recognition sequence identified by Parker et al. (1987) is located in the single-stranded region immediately downstream of stem-loop I (Fig. 1). Within this single-stranded region, nucleotides $28-47$ are abso- 


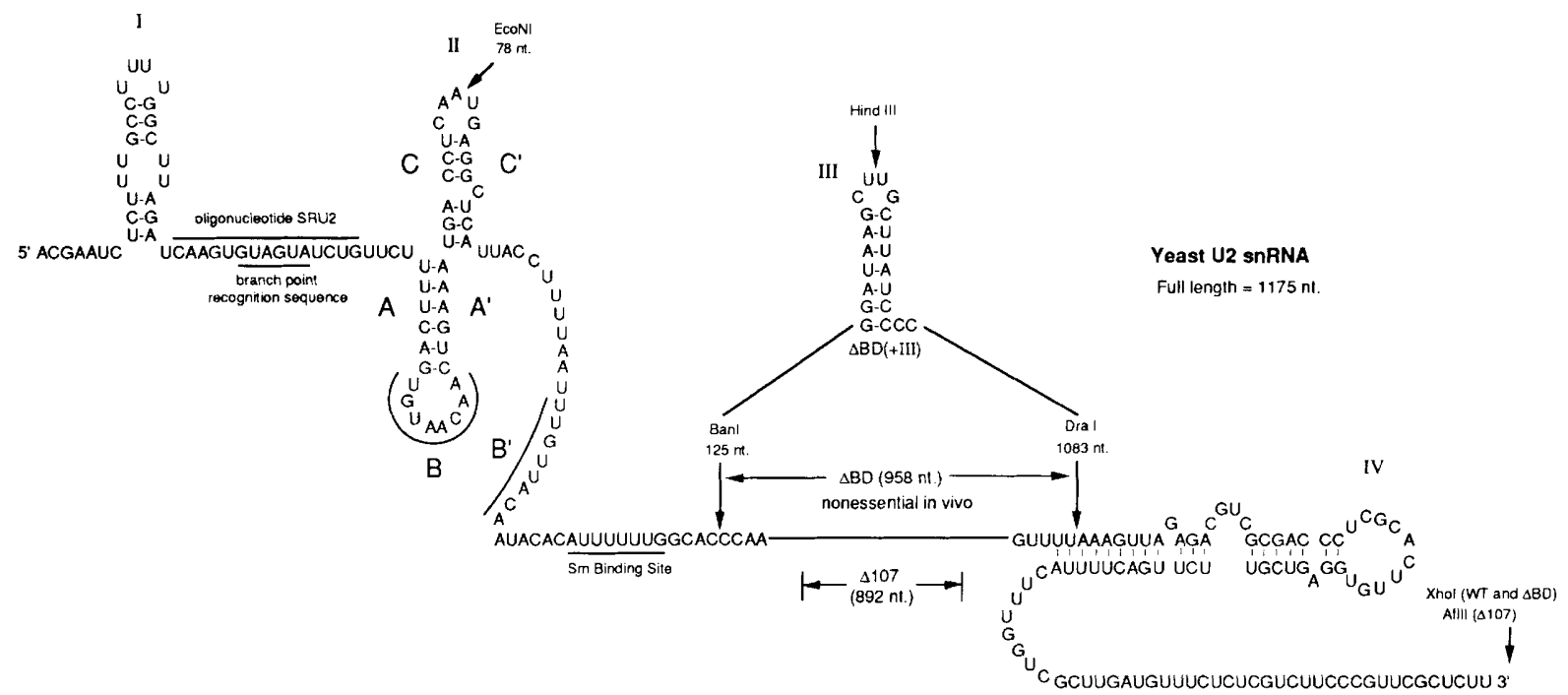

Figure 1. Proposed secondary structure of the yeast U2 snRNA (M. Ares, pers. comm.; Guthrie and Patterson 1988; Ares and Igel 1989). The sequence complementary to the oligonucleotide SRU2 is overlined, and the branchpoint recognition and Sm-binding site sequences are underlined. The regions deleted in the clones $\Delta \mathrm{BD}$ (Igel and Ares 1988) and $\Delta 107$ (Shuster and Guthrie 1988) are shown. Arrows indicate the $3^{\prime}$ ends of the various runoff transcripts described in the text. The sequence of the yeast stem-loop III fragment inserted into the $\triangle B D$ background in the clone YCp545-2 is shown also. The transcript lengths indicated refer to the T7U2 RNA that contains two nucleotides at its $5^{\prime}$ end not found in the authentic yeast U2 snRNA.

lutely conserved in all but one of the U2 snRNAs sequenced thus far (Guthrie and Patterson 1988; Ares and Igel 1989). Ares and Igel (1989) proposed that the stemloop II region of all U2 snRNAs may potentially form a pseudoknot involving helices $\mathrm{AA}^{\prime}, \mathrm{BB}^{\prime}$, and $\mathrm{CC}^{\prime}$, or form either of two alternative hairpin structures, $\mathrm{AA}^{\prime}+\mathrm{BB}^{\prime}$ or $\mathrm{AA}^{\prime}+\mathrm{CC}^{\prime}$ (Fig. 1). The results of in vitro chemical structure probing and in vivo mutational analysis of the yeast U2 snRNA are consistent with the unpseudoknotted structure $\left(\mathrm{AA}^{\prime}+\mathrm{CC}^{\prime}\right)$ depicted in Figure $1(\mathrm{M}$. Ares, pers. comm.). The Sm-binding site sequence $\mathrm{A}(\mathrm{U})_{3-6} \mathrm{G}$, present in all spliceosomal snRNAs except U6, is located downstream from stem-loop II in the yeast U2 snRNA (Fig. 1). In Xenopus oocytes, this sequence is required for binding of the Sm proteins, accumulation of U2 snRNPs in the nucleus, and trimethylation of the $5^{\prime}$ cap of the U2 snRNA (Mattaj and De Robertis 1985; Mattaj 1986). In mammals, the stem-loop III and IV domains of the U2 snRNA are required for binding of the U2 specific proteins, $\mathrm{A}^{\prime}$ and B" (Mattaj and De Robertis 1985; Mattaj 1986; Kleinschmidt et al. 1989; see also Lutz-Reyermuth and Keene 1989). In the yeast U2 snRNA, the region corresponding to domain III is replaced by a large (958-nucleotide) region that is nonessential in vivo (see Fig. 1, Igel and Ares 1988; Shuster and Guthrie 1988). Deletions extending into stem-loop IV of the yeast U2 snRNA cause a decrease both in cell viability and growth rate, as well as causing aberrant $3^{\prime}$ end formation of the U2 snRNA (Shuster and Guthrie 1988; Igel and Ares 1988).

To study further the role(s) of the U2 snRNA in nuclear pre-mRNA splicing, we developed an in vitro system for the functional reconstitution of the yeast $\mathrm{U} 2$ snRNPs. Several groups have described systems for the in vitro reconstitution of mammalian snRNPs with physical and immunological properties identical to authentic snRNPs (Hamm et al. 1987, 1989; Patton et al. 1987; Riedel et al. 1987; Patton and Pederson 1988; Kleinschmidt et al. 1989; Pikielny et al. 1989). However, none of these in vitro assembled snRNPs has been shown to be functional in pre-mRNA splicing. Functional in vivo reconstitution of both $\mathrm{U} 1$ and $\mathrm{U} 2$ snRNPs has been reported on microinjection of HeLa cell Ul or U2 snRNAs into Xenopus oocytes depleted of their endogenous U1 or U2 snRNAs (Pan and Prives 1988). Our overall strategy for reconstitution of functional yeast $U 2$ snRNPs has been to first inactivate the pre-mRNA splicing activity of yeast extracts by oligonucleotide-directed RNase $\mathrm{H}$ cleavage of the endogenous $\mathrm{U} 2$ snRNA. Synthetic yeast U2 RNA, derived by in vitro transcription, is added to the oligonucleotide-treated extracts and the reconstitution of splicing activity assayed. Using this system, we have been able to define regions of the U2 RNA that are required for pre-mRNA splicing activity. In addition, we demonstrate that the effects of point mutations in the U2 RNA can be analyzed using the in vitro reconstitution system. In the accompanying paper by Fabrizio et al. (1989), a similar in vitro reconstitution system for the yeast U6 snRNP is described.

\section{Results}

\section{Inactivation of splicing activity}

Oligonucleotide directed RNase $\mathrm{H}$ cleavage is an efficient technique for depleting specific RNA species from splicing extracts, and has been used to study the involvement of the U1, U2, U4, and U6 snRNAs in pre-mRNA 
splicing (Krämer et al. 1984; Black et al. 1985; Chabot et al. 1985; Krainer and Maniatis 1985; Frendewey et al. 1987; Legrain et al. 1988; Ruby and Abelson 1988; Fabrizio et al. 1989). We used oligonucleotide directed RNase $\mathrm{H}$ cleavage to deplete yeast splicing extracts of their endogenous full-length U2 snRNA, and to consequently inactivate pre-mRNA splicing activity. Several different oligonucleotides (L20B, SRU2, 20SEQ, 20N2, and 20N4, see Materials and methods/ complementary to the $5^{\prime}$ - and $3^{\prime}$-terminal domains of the yeast $U 2$ snRNA were tested for their abilities to cleave the U2 snRNA as judged by Northern hybridization analysis. Only two of the oligonucleotides, L2OB and SRU2, complementary to the the $5^{\prime}$ terminus (nucleotides 1-29) and the branchpoint recognition sequence of the yeast U2 snRNA (nucleotides 29-43), respectively, directed cleavage of the U2 snRNA in splicing extracts. Interestingly, the sizes of the U2 fragments resulting from cleavage with either of these oligonucleotides were identical (data not shown, see below). Cleavage of the U2 RNA mediated by the branch site oligonucleotide SRU2 was much more efficient than that obtained with the oligonucleotide complementary to the $5^{\prime}$ terminus (data not shown). Incubation of yeast splicing extracts with the oligonucleotide SRU2 caused the degradation of the full-length U2 snRNA (1175 nucleotides) into a species $\sim 1070$ nucleotides in length (Fig. 2A). The yeast U1 snRNA is unaffected by this treatment. Approximately $85 \%$ of the full-length U2 snRNA is converted into the shortened form in the presence of ATP and 450 nM SRU2. A small amount of full-length U2 RNA re- mains intact even at substantially higher concentrations of the oligonucleotide (Fig. 2A; see also Legrain et al. 1988). Cleavage of the yeast U2 snRNA by the branch site oligonucleotide (SRU2) is greatly enhanced by the presence of ATP in the cleavage reaction (Fig. 2A), suggesting that ATP induces a change in the accessibility of this region to the oligonucleotide. An identical effect of ATP on the accessibility of the homologous region in the HeLa cell U2 snRNA has been previously noted by Black et al. (1985).

Pre-mRNA splicing activity is also efficiently inactivated by preincubation of extracts with the oligonucleotide SRU2 (Fig. 2B). Routinely, control extracts preincubated in the absence of oligonucleotide convert $55-80 \%$ of the actin pre-mRNA into mature mRNA during the 30-min splicing assay, whereas extracts preincubated in the presence of ATP and $450 \mathrm{~nm}$ SRU2 splice only 5-6\% of the pre-mRNA into mature mRNA. The approximate ninefold reduction in splicing activity correlates well with the approximate sevenfold decrease in the amount of full-length U2 RNA seen by Northern hybridization analysis (Fig. 2A). Incubation of SRU2-treated extracts with DNase I prior to the addition of pre-mRNA substrate has no effect on their splicing activity /data not shown). As expected from the lower cleavage of the U2 RNA in the absence of ATP seen by Northern hybridization analysis (Fig. 2A), preincubation of extracts in the presence of SRU2, but in the absence of ATP, show higher splicing activity than extracts preincubated with SRU2 in the presence of ATP (data not shown). All of the other oligonucleotides tested that failed to direct RNase
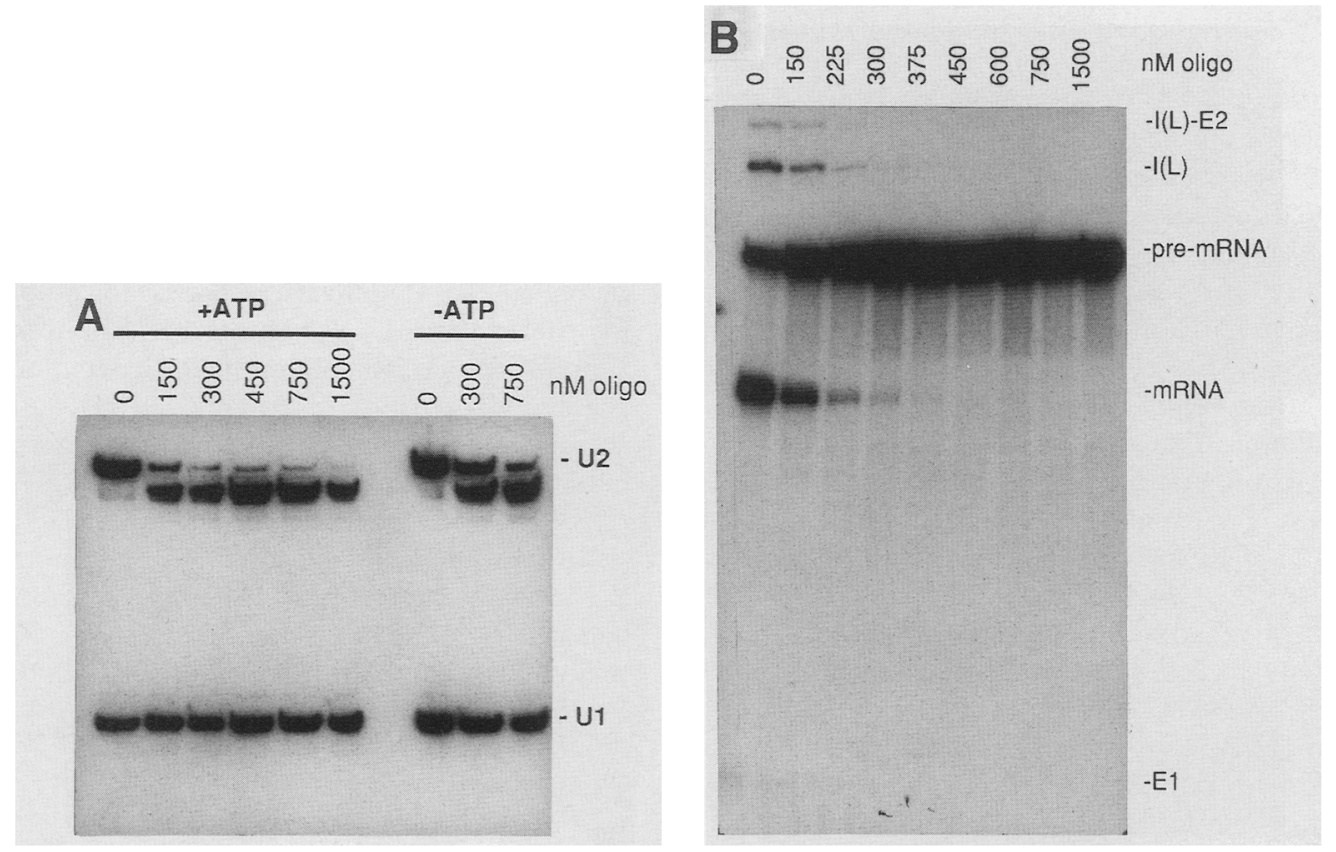

Figure 2. Oligonucleotide-mediated RNase H cleavage of the U2 snRNA and inactivation of splicing activity in yeast splicing extracts. $(A)$ Northern hybridization analysis of the U1 and U2 RNAs after treatment of splicing extracts with the indicated concentrations of the oligonucleotide SRU2 in the presence and absence of ATP. $(B)$ Splicing of actin pre-mRNA in extracts pretreated with the indicated concentrations of the oligonucleotide SRU2 in the presence of ATP. The intron(lariat)-exon 2, intron(lariat), and exon 2 bands are indicated by $\mathrm{I}(\mathrm{L})-\mathrm{E} 2, \mathrm{I}(\mathrm{L})$, and $\mathrm{E} 1$, respectively. 
H cleavage of the U2 snRNA, also failed to inactivate pre-mRNA splicing activity (data not shown).

The oligonucleotide SRU2 is complementary to nucleotides 28-42 of the yeast U2 snRNA (Fig. 1). RNase $\mathrm{H}$ cleavage opposite the oligonucleotide would predict the shortened form of the U2 RNA to be between 1133 and 1147 nucleotides in length. Instead, a species approximately 1070 nucleotides in length is observed, suggesting that the primary RNase $\mathrm{H}$ cleavage product is processed further in the extract. The shortened form of the U2 snRNA resulting from oligonucleotide treatment is very stable in splicing extracts (data not shown), suggesting that it may be stabilized by an association with proteins. Using an oligonucleotide identical to SRU2, Chabot et al. (1985) reported that the RNase H degraded form of the HeLa cell U2 snRNP remains immunoprecipitable by anti-Sm antibodies. Primer extension analysis using U2 RNA isolated from both untreated and SRU2treated yeast splicing extracts shows the predominant $5^{\prime}$ end of the short form of the U2 RNA to be in the sequence, $\mathrm{U} \downarrow$ ACACA $(\mathrm{U})_{6} \mathrm{G}$, immediately upstream of the Sm-binding site (data not shown). No $5^{\prime}$ ends were observed in the region complementary to the oligonucleotide SRU2. A small amount of this U2 species was also seen in the absence of any oligonucleotide treatment (Fig. 2A), suggesting that it may represent a natural intermediate in the degradation of the U2 snRNA.

\section{Reconstitution of functional U2 snRNPs}

For our in vitro reconstitution studies, the gene encoding the yeast U2 snRNA (SNR20; Ares 1986) was subcloned under the control of a T7 promoter. A unique restriction site was placed at the position of the normal $3^{\prime}$ end of the yeast U2 RNA and was used for in vitro runoff transcription (see Materials and methods). The synthetic U2 RNA (T7U2 RNA, 1177 nucleotides) produced by in vitro transcription of this clone is very similar to the authentic yeast U2 snRNA (1175 nucleotides), except that it contains two additional G's at the $5^{\prime}$ terminus and two base substitutions ( $U U \rightarrow G A$ ) at the $3^{\prime}$ terminus.

Incubation of T7U2 RNA in extracts inactivated by pretreatment with $450 \mathrm{nM}$ SRU2 in the presence of ATP can restore splicing activity to the extract (Fig. 3A). Reconstitution is specific for the T7U2 RNA; addition of yeast T7U1 RNA, yeast T7U6 RNA, or Escherichia coli $16 \mathrm{~S}$ and $23 \mathrm{~S}$ rRNA, fails to restore splicing activity in
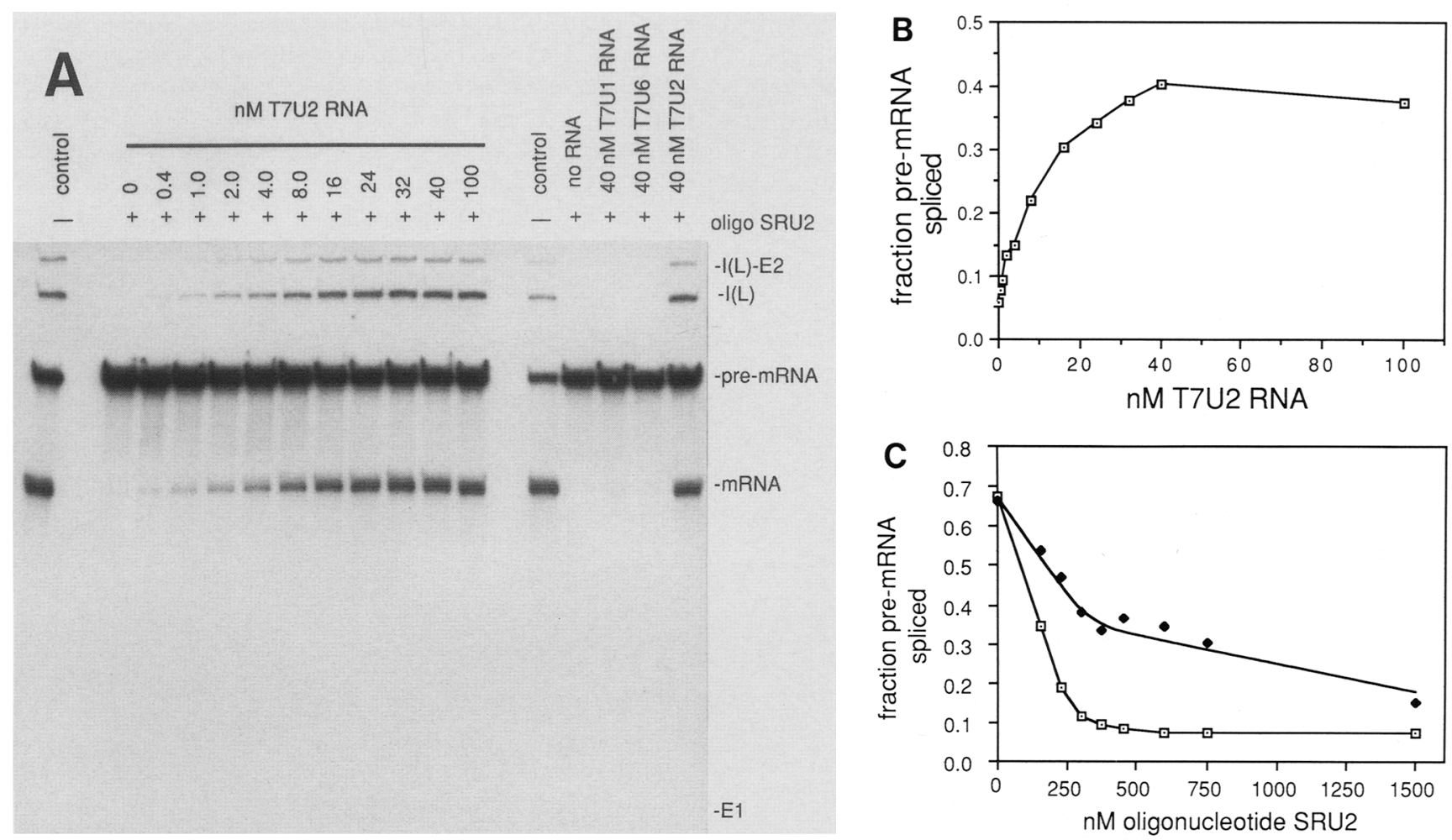

Figure 3. Reconstitution of pre-mRNA splicing activity by synthetic yeast U2 RNA. $(A)$ Reconstitution was performed with the indicated concentrations of T7U2 RNA in extract inactivated with $450 \mathrm{nM}$ SRU2 in the presence of ATP. Splicing activity was assayed using actin pre-mRNA substrate. $(B)$ Graph showing the fraction of spliced pre-mRNA shown in $A$ as a function of the T7U2 RNA concentration used for reconstitution. In this particular experiment, the control (mock-treated) extract spliced $70 \%$ of the pre-mRNA, whereas the SRU2-treated extract alone spliced $6 \%$ of the pre-mRNA. $(C)$ Reconstitution of splicing activity as a function of the oligonucleotide concentration used for inactivation. The oligonucleotide-treated extracts used for Fig. $2 \mathrm{~B}$ were used in in vitro reconstitution reactions with a constant amount of T7U2 RNA $(25 \mathrm{nM})$ and their splicing activities assayed using act in pre-mRNA. The graph shows the fraction of pre-mRNA spliced both with and without subsequent reconstitution as a function of the oligonucleotide concentration used for inactivation of the extract. ( $\square$ ) No added RNA; ( $) 25$ nM T7U2 RNA. 
SRU2-treated extracts (Fig. 3A and data not shown). The maximal level of reconstitution is achieved by the addition of 40 nM T7U2 RNA, where $42 \%$ of the pre-mRNA is spliced (Fig. 3B). Routinely, $55-70 \%$ of the splicing activity observed in the control (mock-treated) extracts is restored by the addition of $40 \mathrm{nM}$ T7U2 RNA. As discussed in detail below, this concentration of T7U2 RNA is substantially higher than the amount of endogenous U2 RNA in the extract prior to oligonucleotide-mediated RNase H cleavage. Kleinschmidt et al. (1989) reported that in vitro assembly of U2 snRNPs in HeLa cell extracts is dependent on the presence of ATP during the reconstitution reaction. Because the depletion of the $\mathrm{U} 2$ snRNA in yeast splicing extracts is greatly enhanced by ATP, we were unable to determine if reconstitution of the yeast U2 snRNP was also ATP dependent.

Reconstitution of splicing activity in extracts depleted of their endogenous U2 RNA by oligonucleotide directed RNase $\mathrm{H}$ cleavage depends on the degradation of the oligonucleotide prior to reconstitution, as any remaining oligonucleotide will also direct the cleavage of added U2 RNA. In the accompanying paper by Fabrizio et al. (1989), we demonstrate that a nuclease activity in yeast splicing extracts can degrade limited quantities of oligonucleotide during the course of normal oligonucleotide-mediated RNase $\mathrm{H}$ depletion reactions. As shown in Figure $3 \mathrm{C}$, the level of splicing activity restored using a constant amount of T7U2 RNA is dependent on the oligonucleotide concentration used for inactivation of the extract. In all of the experiments described below, splicing extracts were inactivated using 450 nM SRU2; at this oligonucleotide concentration, the ratio of splicing activity in the presence and absence of added T7U2 RNA was greatest.

\section{Only a fraction of the T7U2 RNA appears active}

The concentration of endogenous U2 snRNA in the mock-treated (control) reconstitution reactions is ap-

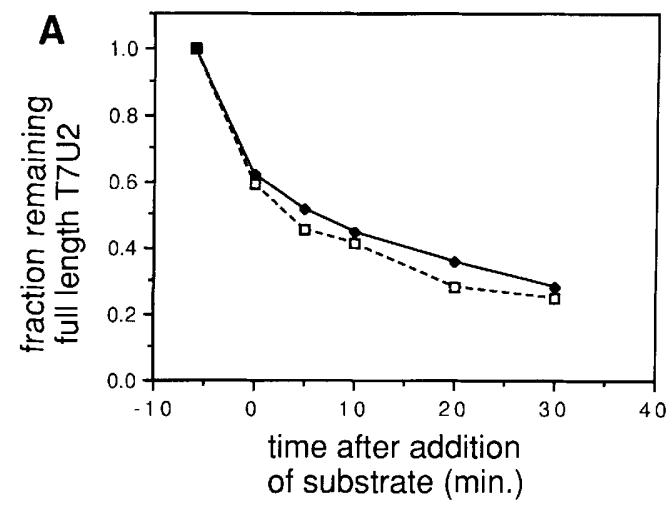

Figure 4. Stability of the full-length T7U2 RNA in extracts pre-treated with $450 \mathrm{~nm}$ oligonucleotide SRU2 in the presence of ATP. (A) Graph showing a time course of the stability of the full-length T7U2 RNA at approximately half-saturating ( $10 \mathrm{nM}$ ) and saturating (40 $\mathrm{nM}$ ) concentrations of T7U2 RNA. The amount of full-length T7U2 RNA is expressed as a fraction of the amount remaining at each time compared to the initial amount (-6 minute sample) (D) $10 \mathrm{nM}$ T7U2; $(-40 \mathrm{nM}$ T7U2. (B) Stability of the full-length T7U2 RNA as a function of the amount of T7U2 RNA used for reconstitution. The indicated amounts of ${ }^{32} \mathrm{P}$-labeled T7U2 RNA were used in the reconstitution assay (input) and the fraction of full-length T7U2 RNA remaining at the end of the standard 30-min splicing assay was determined.

proximately $5 \mathrm{nM}$ as determined by comparison to known amounts of T7U2 RNA in Northern hybridization analyses (data not shown). This is approximately eight times lower than the concentration of T7U2 RNA (40 $\mathrm{nM}$ ) necessary for the maximum reconstitution of splicing activity in extracts treated with 450 nM SRU2. The higher amount of T7U2 RNA required for maximal reconstitution may be attributable to several factors. First, the stable 1070-nucleotide fragment of the endogenous U2 RNA resulting from RNase $\mathrm{H}$ digestion may act as a competitive inhibitor during reconstitution with the synthetic U2 RNA. Second, reconstitution of splicing activity is a function of the oligonucleotide concentration used for inactivation of the extract, and any oligonucleotide remaining at the beginning of the reconstitution reaction may cause the degradation of the added T7U2 RNA. This appears to be only a minor problem when $450 \mathrm{~nm}$ SRU2 is used for inactivation of extracts, since substantial splicing activity can be reconstituted using low concentrations of T7U2 RNA (i.e., 8 nM, Fig. 3). In addition, when a saturating amount of T7U2 RNA is used for reconstitution (40 nM), only about $15 \%$ of the initial amount of T7U2 RNA in the reaction is degraded into the shortened ( 1070-nucleotide) species, which most likely results from oligonucleotidemediated RNase $\mathrm{H}$ cleavage of T7U2 RNA assembled into U2 snRNPs (data not shown). Third, nucleases in the extract may degrade a substantial proportion of the T7U2 RNA before it can be stabilized by incorporation into RNPs. Degradation of ${ }^{32}$ P-labeled T7U2 RNA was followed during the course of the reconstitution reaction using approximately half-saturating $(10 \mathrm{nM})$ and saturating (40 nM) concentrations of ${ }^{32}$ P-labeled T7U2 RNA (Fig. 4A). At both concentrations tested, a significant and constant proportion $(\sim 40 \%)$ of the input full-length T7U2 RNA was degraded during the 6-min preincubation prior to the addition of unlabeled actin pre-mRNA substrate. The addition of substrate slows the degradation of the remaining full-length T7U2 RNA. At the end

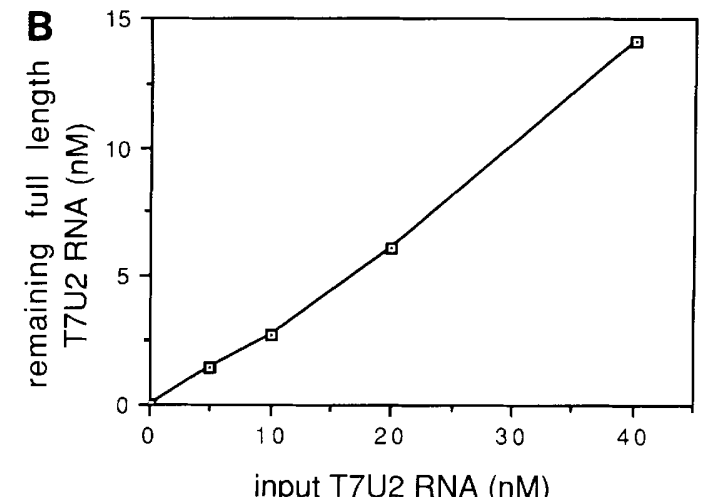


of the reconstitution assay, almost identical proportions of the input full-length T7U2 RNA remained at both of the concentrations tested, demonstrating that nucleases in the extract are present in excess. This experiment was repeated using several different concentrations of T7U2 RNA, and the amount of full-length T7U2 RNA remaining at the end of the normal reconstitution assay was measured (Fig. 4B). At all of the concentrations tested, approximately $35 \%$ of the initial amount of fulllength T7U2 remained at the end of the reconstitution assay. The finding suggested a fourth possibility: Only $\sim 35 \%$ of the T7U2 RNA may be in an active form, whereas $\sim 65 \%$ of the T7U2 RNA is in an inactive form. This may account, at least in part, for the approximately eightfold excess of T7U2 RNA (over endogenous U2 RNA) required for the maximal reconstitution of splicing activity. One possible cause of inactivity may be errors in the primary sequence of the T7U2 RNA resulting from misincorporation during in vitro transcription. Although the in vitro error rate of T7 RNA polymerase is unknown, this enzyme has been observed to slip when it encounters runs of either As or Ts in its template (Reyes and Abelson 1988; D.S. McPheeters and L. Gold, unpubl.). Several long stretches of $U$ (up to 8 bases in length) are present in the full-length T7U2 RNA. Inactivity may also be caused by incorrect folding of the T7U2 RNA. The T7U2 RNA (as well as the other RNAs) used in this study was purified using denaturing conditions, and therefore is likely to be represented in at least several different conformations. Increasing the proportion of correctly folded T7U2 RNAs should decrease the concentration of RNA required for reconstitution of maximal splicing activity. Preliminary renaturation experiments with the T7U2 RNA have failed to identify conditions that significantly lower the concentration of RNA required to obtain maximal splicing activity (data not shown).

\section{Modification of the T7U2 RNA}

The yeast U2 snRNA in splicing extracts can be immunoprecipitated with antibodies directed against the $5^{\prime}$ cap nucleotide 2,2,7-trimethyl guanosine, characteristic of snRNAs. Therefore, we compared the activities and stabilities of T7U2 RNAs transcribed in the presence and absence of $\mathrm{m}^{7} \mathrm{GpppG}$ in the in vitro reconstitution assay. No significant differences in the activities or stabilities of the $\mathrm{m}^{7} \mathrm{GpppG}$ capped and uncapped T7U2 RNAs were detected (data not shown). In addition to a $5^{\prime}$ cap nucleotide, yeast snRNAs contain several types of base modifications (Wise et al. 1983); both human and rat U2 snRNAs contain a large number of base modifications, including pseudouridine and 2'-O-methylated residues (for review, see Reddy and Busch 1988). Therefore, we tried to determine whether an active deletion derivative of the T7U2 RNA (T7 107, see below) was modified during the course of the reconstitution assay using twodimensional chromatographic analysis. No 2'-O-methyl modifications were detected, however, approximately 0.5 moles of pseudouridine per mole of $\mathrm{T} 7(\Delta 107) \mathrm{U} 2$

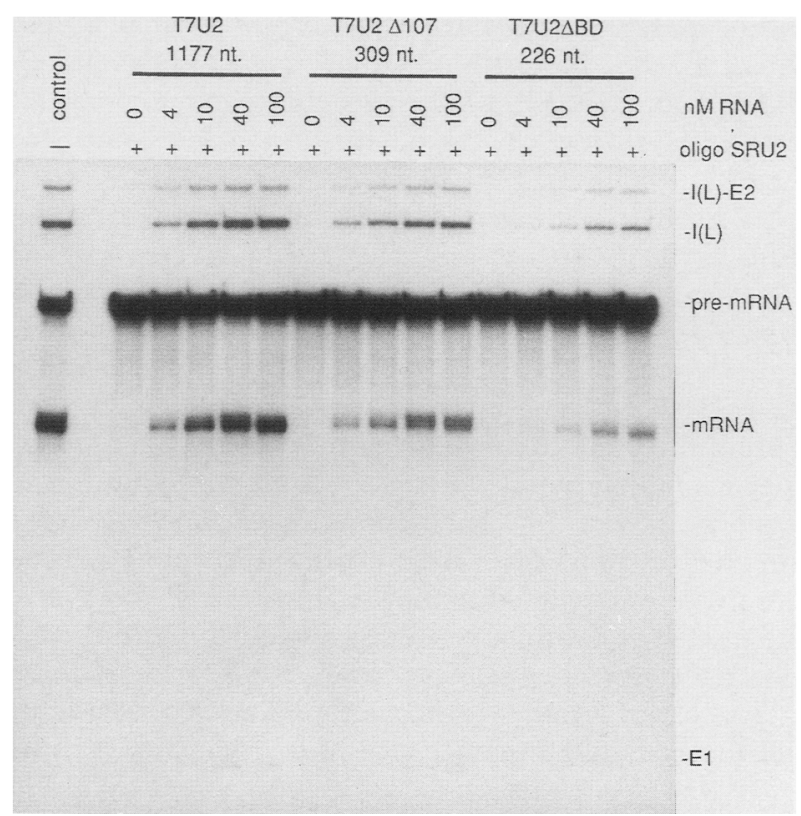

Figure 5. Splicing activities of yeast T7U2 RNAs containing large internal deletions in the reconstitution assay. Yeast splicing extract was pretreated using $450 \mathrm{~nm}$ oligonucleotide SRU2 in the presence of ATP. Reconstitution was then performed using the various concentrations of RNAs indicated and splicing activity assayed using wild-type actin pre-mRNA. The regions deleted in the $\Delta 107$ and $\triangle \mathrm{BD}$ RNAs are indicated in Fig. 1.

RNA were found in the RNA that remained after the reconstitution assay (data not shown). The exact position of the pseudouridine modification(s) was not determined, and it is unknown if modification occurred at identical sites in each synthetic U2 RNA molecule.

\section{Splicing activities of internal T7U2 deletions}

On the basis of the unusually large size of the yeast U2 snRNA (1175 nucleotides) and its sequence and structural similarities to mammalian U2 RNAs $\{\sim 188 \mathrm{nu}-$ cleotides|, several investigators have constructed large internal deletions in the gene encoding the yeast U2 snRNA (SNR20), which proved to be viable when introduced back into yeast (Igel and Ares 1988; Shuster and Guthrie 1988). Two of these large internal deletions were subcloned under the control of $\mathrm{T} 7$ promoters and assayed for their ability to function in the in vitro reconstitution system. $\Delta 107$ (Shuster and Guthrie 1988) removes 892 nucleotides of internal U2 sequence, and $\triangle \mathrm{BD}$ (Igel and Ares 1988) overlaps both end points of $\Delta 107$ and removes 958 nucleotides of internal U2 sequence (see Fig. 1). Reconstitution using varying amounts of each of these internal deletion RNAs is shown in Figure 5. In this experiment, the control (mock-treated) extract spliced $70 \%$ of the precursor mRNA, whereas the SRU2-treated extract alone spliced only $5 \%$ of the precursor mRNA. Addition of $100 \mathrm{nM}$ full-length T7U2, T7 107 , or T7 $\triangle B D$ RNA to SRU2- 
treated extract resulted in the splicing of $36 \%, 24 \%$, and $16 \%$ of the pre-mRNA, respectively. The T7U2, $\mathrm{T} 7 \Delta 107$, and $\mathrm{T} 7 \mathrm{BD}$ RNAs all exhibit roughly similar stabilities during the reconstitution assay (data not shown).

To further investigate the role of the sequences deleted in the T7 107 and T7 $\triangle B D$ RNAs, a variant of the $\triangle \mathrm{BD}$ clone was tested. A homolog of the conserved U2 stem-loop III structure has been identified within the region deleted in both $\triangle 107$ and $\triangle \mathrm{BD}$ (Guthrie and Patterson 1988; Ares and Igel 1989|. A small fragment containing the yeast homolog of stem-loop III has been inserted immediately downstream of the Sm-binding site sequence in the $\triangle \mathrm{BD}$ background in plasmid yCp545-2 (supplied by M. Ares). The RNA from this clone should closely resemble mammalian U2 snRNA in both size and predicted secondary structure (see Fig. 1). A T7 promoter was attached to this clone using standard polymerase chain reaction (PCR) methodology (see Materials and methods), and the activity of the resultant $T 7 \triangle B D$ (+III) RNA tested in the U2 reconstitution assay. Addition of stem-loop III to the T7 $\triangle B D$ RNA did not affect the maximum level of splicing activity obtained in the reconstitution assay. Interestingly however, addition of stem-loop III to the T7 $\triangle \mathrm{BD}$ RNA lowered the concentration of RNA required for maximal reconstitution of splicing activity approximately twofold (data not shown).

\section{Splicing activities of $3^{\prime}$ truncated T7U2 RNAs}

In vivo analysis of deletion derivatives of the gene for the yeast U2 snRNA (SNR20), has suggested that ele-

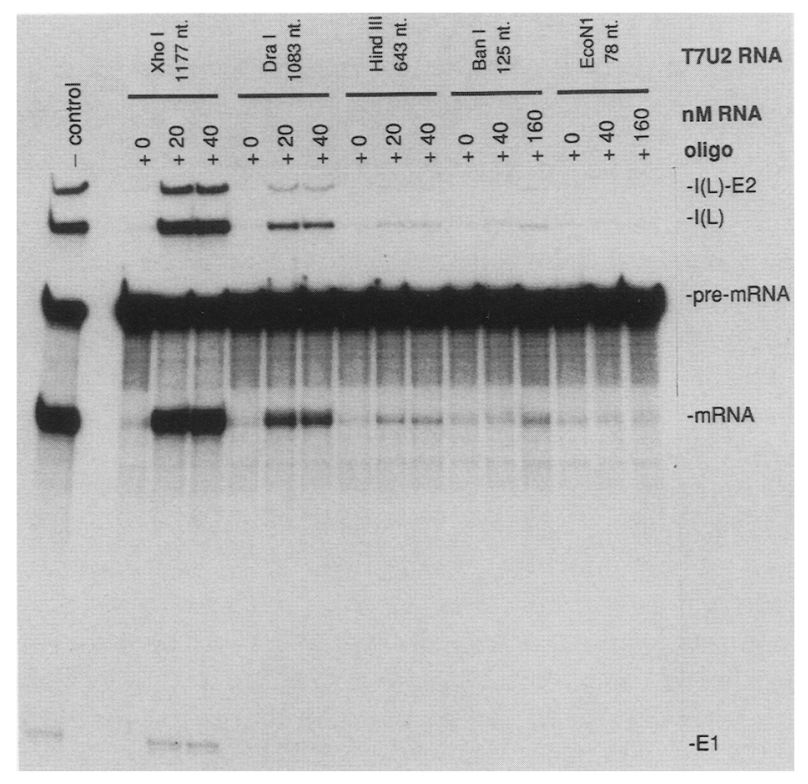

Figure 6. Splicing activities of $3^{\prime}$-truncated yeast T7U2 RNAs. Yeast splicing extract was pre-treated using $450 \mathrm{nM}$ oligonucleotide SRU2 in the presence of ATP. Reconstitution was then performed using the various concentrations of RNAs indicated and splicing activity assayed using wild-type actin pre-mRNA. The locations of the $3^{\prime}$ ends of the RNAs used are indicated in Fig. 1. ments near the $3^{\prime}$ terminus of the yeast U2 snRNA, including perhaps all of domain IV, are required for proper 3 '-end formation (Shuster and Guthrie 1988; Igel and Ares 1988). The in vivo data have also suggested that the nonconserved 3 '-terminal $10-15$ nucleotides of the yeast U2 snRNA are dispensable for function (Igel and Ares 1988). We have investigated the role of sequences in the $3^{\prime}$-terminal domain of the yeast U2 snRNA in pre-mRNA splicing using the in vitro reconstitution assay. Analysis of the 3 -terminal domain in the in vitro reconstitution system has the advantage that sequences necessary for proper 3 '-end formation of the U2 snRNA in vivo are not required. T7U2 RNA was truncated to varying extents at its $3^{\prime}$ end by performing in vitro transcription with template DNAs cut at the restriction sites indicated in Figure 1. The 3 '-truncated synthetic U2 RNAs then were tested for their abilities to reconstitute pre-mRNA splicing activity in SRU2 treated extract (Fig. 6). In this experiment, the control (mock-treated) extract spliced $80 \%$ of the pre-mRNA, whereas the SRU2-treated extract alone spliced $5-6 \%$ of the precursor mRNA. Although stem-loop IV of the yeast U2 snRNA is completely deleted in the T7U2 DraI RNA, this RNA functions well in the reconstitution assay, splicing $12 \%$ of the pre-mRNA. Reconstitution performed with either HindIII (643 nucleotides) or BanI (125 nucleotides) T7U2 RNA resulted in the splicing of $8 \%$ of the pre-mRNA. Although the level of splicing observed with the HindIII and BanI T7U2 RNAs was consistently low, it was always noticeably higher than the background levels of pre-mRNA splicing. Further truncation of the T7U2 RNA, resulting in deletion of the Sm-binding site (EcoNI, 78 nucleotides), completely abolishes any reconstitution of splicing activity. With the exception of the EcoNI transcript, all of the 3'-truncated T7U2 RNAs exhibit stabilities similar to that of the full-length T7U2 RNA during the reconstitution assay (data not shown). The extreme instability of the EcoNI T7U2 RNA is most likely a consequence of an inability to bind $\mathrm{Sm}$ proteins. This instability prevents an accurate assessment of its ability to function in premRNA splicing.

\section{Splicing activities of heterologous U2 snRNAs}

The primary sequences of the $5^{\prime}$-terminal domains of the U2 RNAs from yeast, human, rat, and Caenorhabditis elegans are all highly conserved, whereas primary sequences of their $3^{\prime}$ terminal domains are much more divergent (Guthrie and Patterson 1988). Synthetic U2 RNAs from yeast, human (HeLa cells), and C. elegans snRNA were tested for their abilities to reconstitute splicing activity in SRU2-treated yeast splicing extracts (Fig. 7). Both the rat and HeLa cell U2 RNAs were able to reconstitute small amounts of pre-mRNA splicing activity, whereas the synthetic $C$. elegans U2 RNA fails to restore any activity. Both the rat and HeLa cell U2 RNAs restored similar maximum levels of splicing activity to SRU2-treated yeast extracts, although the amount of each RNA required to restore this activity differed substantially. 


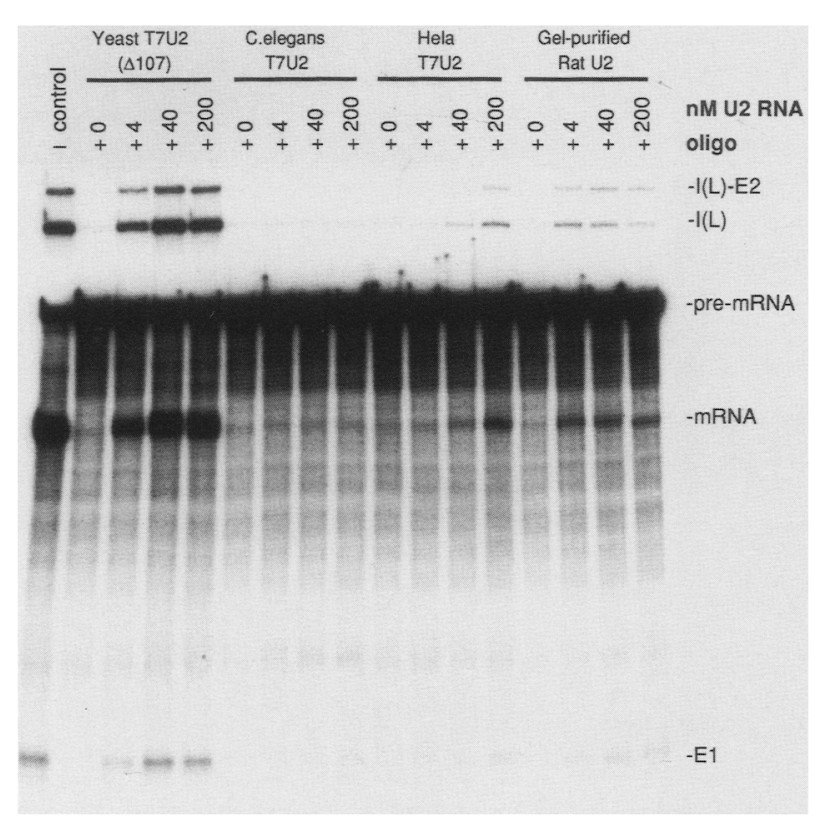

Figure 7. Splicing activities of heterologous U2 RNAs in yeast splicing extracts. Yeast splicing extract was pretreated using $450 \mathrm{nM}$ oligonucleotide SRU2 in the presence of ATP. Reconstitution was performed using the various concentrations of RNAs indicated and splicing activity assayed using wild-type actin pre-mRNA.

\section{In vitro suppression of branch site mutations}

Using yeast strains bearing mutations within the branch site (UACUAAC) sequence of actin-HIS4 fusions, Parker et al. (1987) demonstrated allele-specific suppression of these mutations by the introduction of compensatory mutations on plasmid-borne yeast U2 genes. The suppression of these branchpoint mutations is diagrammed in Figure $8 \mathrm{~A}$. To demonstrate the usefulness of the in vitro reconstitution system for the analysis of point mutations in the yeast U2 RNA, we repeated the branch site suppression experiments of Parker et al. (1987) using the in vitro system (Fig. 8B). Reconstitution in SRU2treated extracts was performed using either T7U2(WT), T7U2(U36), or T7U2(U37) RNAs. Splicing activities of the reconstituted extracts were then assayed using wildtype (WT), A256, and A257 actin pre-mRNA substrates. All of the pre-mRNA substrates used in this experiment contained the $\Delta 6$ mutation, which removes a cryptic branchpoint sequence (UACUAAG) that can be used on mutation of the normal branch site sequence (Vijayraghavan et al. 1986; Cellini et al. 1986). With the WT actin pre-mRNA substrate, substantial splicing activity is seen only with the T7U2(WT) RNA. The heavy background splicing activity in Figure $8 \mathrm{~B}$ is attributable to long exposure of the film. Very little increase in splicing activity is seen in the reactions with either the T7U2/U36) or T7U2(U37) RNAs. Using the A256 substrate, splicing is completely abolished in the control (mock-treated) reaction, as well as in the reconstitution reactions using T7U2(WT) or T7U2(U36) RNAs. Weak, but specific suppression of the A256 mutation is observed with the T7U2(U37) RNA, as evidenced by the appearance of intron(lariat)-exon2 [I(L)-E2] and intron(lariat) $[\mathrm{I}(\mathrm{L})]$ RNAs. With the A257 substrate, splicing is completely abolished in the control reaction and in the reactions reconstituted with either the T7U2(WT) or T7U2/U37) RNAs. Weak, but specific suppression of the A257 mutation is observed with the T7U2(U36) RNA. Interestingly, a slight accumulation of the $I(L)-E 2$ intermediate is seen. In lighter exposures of the gel shown in Figure $8 \mathrm{~B}$, no accumulation of the $\mathrm{I}(\mathrm{L})$ E2 intermediate is seen in the low level of splicing of the WT pre-mRNA by the T7U2(U36) RNA. Qualitatively similar suppressions of the A256 and A257 mutations were obtained with the U37 and U36 mutations in the $\mathrm{T} 7 \Delta 107$ background, respectively (data not shown).

\section{Discussion}

We have demonstrated that reconstitution of splicing activity in yeast splicing extracts depleted of their endogenous U2 snRNA by oligonucleotide-directed RNase $H$ cleavage can be achieved by the addition of synthetic U2 RNAs. The ability to reconstitute splicing activity with synthetic U2 RNAs has allowed the regions of the yeast U2 snRNA required for pre-mRNA splicing activity in vitro to be determined. The in vitro system described in this paper has several advantages over in vivo systems for studying the U2 snRNA. Features required for proper function in vivo, such as those required for proper 3 '-end formation and nuclear transport, are not required in vitro.

Although the yeast U2 snRNA is over six times larger than its mammalian counterpart (Ares 1986), our results suggest that the yeast U2 snRNP is structurally similar to the mammalian U2 snRNP. As with the mammalian U2 snRNP, the accessibility of the single-stranded region of the yeast $\mathrm{U} 2$ snRNA containing the branchpoint recognition sequence to oligonucleotide-mediated RNase $\mathrm{H}$ cleavage is greatly enhanced by the presence of ATP. In addition, the position of the secondary cleavage found immediately upstream from the Sm-binding site sequence in the yeast U2 snRNA after RNase H cleavage is practically identical to the $5^{\prime}$ ends of the fragments found in nuclease protection experiments with both core and native HeLa cell U2 particles (Liautard et al. 1982; Reveillaud et al. 1984). The oligonucleotide-mediated RNase $\mathrm{H}$ cleavage and subsequent processing of approximately $15 \%$ of the T7U2 RNA into a species resembling the protected fragment of the endogenous U2 snRNA, shows that a portion of the T7U2 RNA is assembled into $\mathrm{U} 2$ snRNPs during the reconstitution assay.

Using both internal, and $3^{\prime}$-terminal deletions in the synthetic yeast U2 RNA, we demonstrated that only the highly conserved $5^{\prime}$ terminal 123 nucleotides of the yeast U2 RNA are required for in vitro pre-mRNA splicing activity. Two large internal deletions of the yeast U2 RNA, both previously shown to be viable in yeast (Igel and Ares 1988; Shuster and Guthrie 1988), have reduced activities in the in vitro reconstitution 

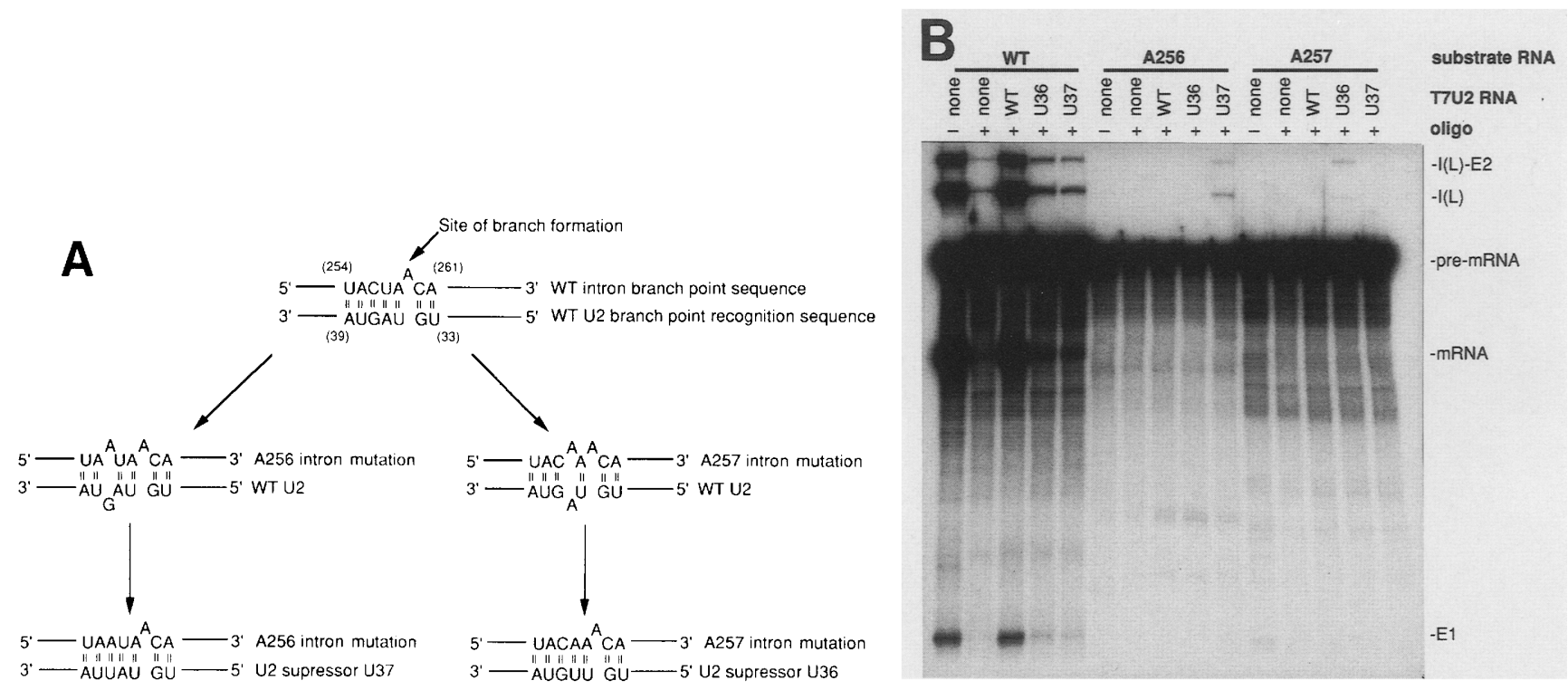

Figure 8. In vitro suppression of pre-mRNA branch sequence mutations. (A) Base-pairing of the pre-mRNA branch-site sequence and the U2 snRNA showing the mutations used in vivo by Parker et al. (1987) and in the in vitro reconstitution experiment described in $B$. (B) In vitro suppression of the A256 and A257 branch-site mutations in reconstitution reactions performed with T7U2/WT), T7U2/U36), and T7U2/U37) RNAs. Yeast splicing extract was pre-treated using $450 \mathrm{~nm}$ oligonucleotide SRU2 in the presence of ATP. Then, reconstitution was performed with $40 \mathrm{nM}$ each of the T7U2 RNAs indicated and splicing activity assayed using labeled WT( $\Delta 6)$, A256 $(\Delta 6)$, and A257( $\Delta 6)$ actin pre-mRNAs.

system when compared with the full-length U2 RNA. The reduced activities of both the T7 107 and $T 7 \Delta B D$ RNAs, along with the unusual behavior of the T7DBD (+III) RNA, suggest that a portion of the nonessential region corresponding to domain III in the yeast U2 RNA may be directly involved in the assembly of the U2 snRNP. Alternatively, the nonessential region in the yeast U2 snRNA may play a more indirect role by correctly positioning stem-loop IV with respect to the $5^{\prime}$ terminal domain of the U2RNA. Using synthetic U2 transcripts containing 3 '-terminal deletions, we have clearly shown that stem-loop IV of the yeast U2 RNA is not required for pre-mRNA splicing activity; the T7U2 DraI RNA, which lacks stem-loop IV, shows significant splicing activity. Very low splicing activity was observed with the HindIII (643 nucleotides) and BanI (125 nucleotides) T7U2 RNAs in the in vitro system. This result is consistent with both the splicing activities, and the regions deleted from the T7 $\mathrm{BD}$ and T7U2 DraI RNAs. Although sequences $3^{\prime}$ to the Sm-binding site appear to significantly influence the level of splicing activity obtained in vitro, only the highly conserved 5 '-terminal domain of the yeast U2 RNA appears to be absolutely required for pre-mRNA splicing activity; however, our experiments do not rule out the possibility that reconstitution of splicing activity may result from formation of hybrid U2 snRNPs containing the $5^{\prime}$-terminal domain of the synthetic U2 RNA and the stable 1070-nucleotide 3 '-terminal fragment of endogenous U2 RNA (i.e., transcomplementation). All of the synthetic yeast U2 RNAs that are active in our in vitro reconstitution system contain the highly conserved Sm-binding site sequence.
Although this sequence is required for both cap trimethylation and nuclear transport in vivo, it is unknown whether the association of $\mathrm{Sm}$ proteins with this sequence is required for catalytic function (see Guthrie and Patterson 1988). Experiments to address this question are currently being done using the in vitro U2 reconstitution system.

In a comparison of U2 snRNA sequences from 12 different species, Guthrie and Patterson (1988) found that the $5^{\prime}$-terminal domain of U2 snRNAs is remarkably conserved. Consistent with this observation and our finding that only the $5^{\prime}$-terminal domain of the yeast U2 RNA is required for splicing activity, we found that U2 RNAs from both humans and rats can function, albeit poorly, in the yeast extracts. We were unable to reconstitute splicing activity in yeast extracts using a synthetic C. elegans U2 RNA. The major differences in the sequences of the yeast, HeLa cell, rat and C. elegans U2 snRNAs are all located in the region $3^{\prime}$ to the Smbinding site (see Guthrie and Patterson 1988; Ares and Igel 1989). Two U2-specific proteins, termed A' and B", are known to interact with the $3^{\prime}$-terminal domain of mammalian U2 snRNAs and may interact with the Sm proteins as well (Mattaj and De Robertis 1985; Mattaj 1986; Kleinschmidt et al. 1989; see also Lutz-Reyermuth and Keene 1989). The low activities of the HeLa cell and rat U2 RNAs in the yeast reconstitution system suggest that the proteins in yeast homologous to the mammalian $\mathrm{A}^{\prime}$ and $\mathrm{B}^{\prime \prime}$ proteins may not interact efficiently with the poorly conserved primary sequences in the $3^{\prime}$-terminal domains of these heterologous U2 RNAs.

The 5'-terminal domains of both the human and rat 
U2 snRNAs contain a large number of modified bases (Reddy and Busch 1988). Yeast snRNAs also contain base modifications, but the locations of these modifications are unknown (see Wise et al. 1983). Our results show that a small fraction of the uridines in the synthetic yeast U2 RNA are replaced by pseudouridine during the reconstitution assay. Because only a fraction of the T7U2 RNA appears to be active in the reconstitution assay, the relationship of observed pseudouridine incorporation to splicing activity is unclear. Substoichiometric pseudouridine formation in a synthetic U2 RNA has also been observed during the in vitro assembly of U2 snRNPs in HeLa cell extracts (Kleinschmidt et al. 1989). Although the exact function of the base modifications in snRNAs is unknown, they may be important for finely adjusting the conformation of the RNA by altering the stacking of adjacent bases, or they may act to prevent aberrant reactions from occurring during splicing.

We have demonstrated that analysis of point mutations in the in vitro $U 2$ reconstitution system will be useful for identifying nucleotides in the U2 snRNA directly involved in pre-mRNA splicing by duplicating the in vivo suppression experiments of Parker et al. (1987). The introduction of the U36 and U37 mutations into the T7U2 RNA resulted in very specific, albeit weak, suppression of the pre-mRNA branch site mutations, A257 and A256, respectively. Neither the T7U2(U36) or T7U2/U37) suppressor RNAs spliced wild-type actin pre-mRNA efficiently. The slight accumulation of intron(lariat)-exon2 intermediate during the splicing of the A257 pre-mRNA in the reconstitution reaction performed with the T7U2(U36) RNA, but not with wildtype pre-mRNA, suggests that the A257 mutation itself affects the second step of pre-mRNA splicing. Although it is difficult to compare the levels of suppression observed in vitro and in vivo, we feel that several factors may have contributed to the weak in vitro suppression observed. First, the effects of intron mutations on splicing in vitro are usually more severe than those seen in vivo (Vijayraghavan et al. 1986). Second, the weak in vitro suppression of the A256 and A257 mutations is consistent with the effects of these branch site mutations on the binding of the U1 snRNP to pre-mRNA observed in solid phase splicing experiments (Ruby and Abelson 1988). Finally, the low in vitro suppression efficiency may be accentuated by a lack of base modifications in the suppressor T7U2 RNAs. The branch site recognition regions of both the human and rat U2 snRNAs are heavily modified (Reddy and Busch 1988). In transfer RNAs, base modifications in the anticodon stem and loop appear to alter the stacking of nearby bases in the anticodon and thus modulate base-pairing interactions (reviewed in Adamiak and Gornicki 1985).

We believe that because of its role in binding of the branch-site sequence, a portion of the U2 snRNA must be intimately involved in the formation of an active site in the spliceosome and may even participate directly in the catalysis of pre-mRNA splicing. During inspection of the consensus structures for the spliceosomal
snRNAs proposed by Guthrie and Patterson (1988), we were struck by the absolute sequence conservation of the 20 nucleotides in the single-stranded region encompassing the branchpoint recognition sequence (nucleotides 28-47) in the U2 snRNAs from 11 of 12 different species. Even in the species Trypanosoma brucei, in which this region is kept from being absolutely conserved, the sequence matches the consensus at 14 of 20 positions. This highly conserved region of both the yeast and HeLa cell U2 snRNAs is highly susceptible to oligonucleotide-mediated RNase $\mathrm{H}$ cleavage in the presence of ATP, and therefore must be exposed during spliceosome assembly. If any interactions between the U2 snRNP and other snRNPs were mediated by the formation of RNA-RNA duplexes, this exposed region of the U2 snRNA would be an ideal candidate for the formation of such base-pairing interactions. Comparison of the complement of this highly conserved 20 nucleotide sequence in U2 RNA to the consensus sequences of the other spliceosomal snRNAs /Guthrie and Patterson 1988) revealed a potential base-pairing interaction with an absolutely conserved sequence in the central domain of the U6 snRNA (Fig. 9). This potential U2/U6 interaction involves base-pairing of the sequence ACAGA, in the central domain of the U6 snRNA with the sequence UCUGU, immediately downstream from the branchsite recognition sequence in the U2 snRNA. Like the branch-site recognition region of the U2 snRNA, the accessibility of this region in the central domain of the yeast U6 snRNA to oligonucleotide-mediated RNase $\mathrm{H}$ cleavage is ATP dependent (Fabrizio et al. 1989). With the exception of position 39 in the U2 RNA from $T$. brucei, all of the nucleotides involved in the proposed U2/U6 interaction are absolutely conserved (see Fig. 9). In the trans-splicing $T$. brucei, the proposed interaction of the U2 and U6 snRNAs could potentially be maintained by shifting the helix depicted in Figure 9 one nucleotide to the right, so that $\mathrm{U}(43)$ in the T. brucei $\mathrm{U} 2$ RNA would base-pair with $\mathrm{A}(46)$ in its U6 snRNA. Although this potential U2/U6 interaction is predicted to be weak, several of the nucleotides involved are known to be modified (see Reddy and Busch 1988) and this may help stabilize the interaction. Interestingly, all of the regions of the spliceosomal snRNAs known to participate in RNA-RNA interactions, including the $5^{\prime}$ end of the U1 RNA and the branch-site recognition region of the U2 snRNA, are heavily modified in the snRNAs in which the positions of base modifications have been determined (for review, see Reddy and Busch 1988). Although the function of the U6 snRNA in pre-mRNA splicing is unknown, it is the most highly conserved spliceosomal RNA and has been proposed to have a fundamental role in nuclear pre-mRNA splicing (Brow and Guthrie 1989). Recently, it was discovered that the Schizosaccharomyces pombe U6 snRNA contains a nuclear pre-mRNA-like intron (Tani and Ohshima 1989). This finding prompted Brow and Guthrie (1989) to speculate that this intron may have been inserted into the $S$. pombe U6 RNA during an aberrant splicing reaction, and that the site of insertion of this intron could reflect 


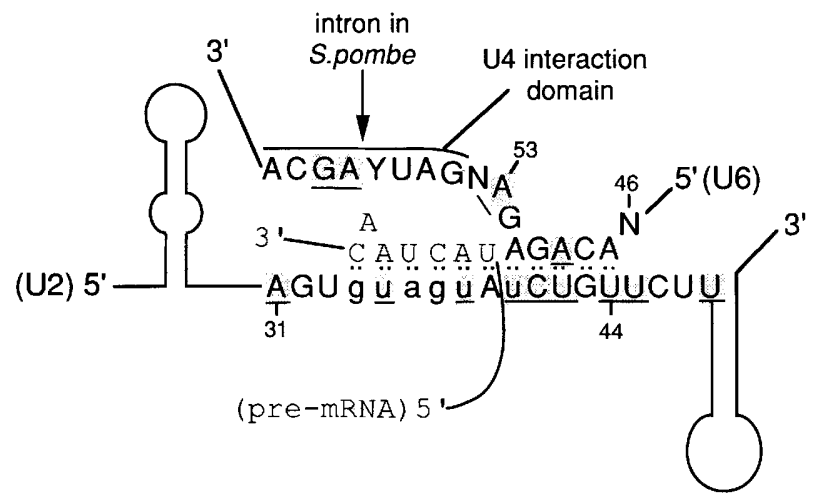

Figure 9. Proposed interaction of the U2 and U6 snRNAs. The nucleotide numbering refers to the $S$. cerevisiae $\mathrm{U} 2$ and $\mathrm{U} 6 \mathrm{se}-$ quences. Invariant bases in the U2 and U6 snRNA sequence alignments of Guthrie and Patterson (1988) are indicated by capital letters, whereas bases that are invariant in all but one of the U2 and U6 sequences examined by Guthrie and Patterson (1988) are indicated by lower case letters. Bases that are modified in either the human or rat U2 and U6 snRNAs are underscored (from Reddy and Busch 1988).

the proximity of this region of $\mathrm{U} 6$ to the catalytic center of the spliceosome. One consequence of the model for the proposed U2/U6 interaction shown in Figure 9 is that it potentially places the site of insertion of this intron in very close proximity to the adenosine in the premRNA that will participate in formation of the $2^{\prime}(\mathrm{A})-$ $5^{\prime}(G)$ branch. The availability of systems for the functional in vitro reconstitution of both the yeast U6 (Fabrizio et al. 1989) and U2 snRNPs will allow the proposed base-pairing of the U2 and U6RNAs depicted in Figure 9 to be tested.

\section{Materials and methods Oligonucleotides}

The following oligonucleotides $\left(5^{\prime}-3^{\prime}\right)$ were synthesized on an Applied Biosystems model 380A DNA synthesizer and were used in this study: SRU2, CAGATACTACACTTG; L20T, GTAAT ACGAC TCACT ATAGG ACGAA TCTCT TTGCCTTTTGGCTTA; L20B， GATCTAAGCCAAAAGGCAAAGAGATTCGTCCTATAGTGAGTCGTATTACTGCA; 20N1, CGCGACCCTCGCACTTGTGGAGTCGTTCTTGACTTTTACTTTGG; 20N2, CAAGCGACCAAAGTAAAAGTCAAGAACGACTCCACAAGTGCGAGGGTCGCGACGT; 20N3, TCGCTTGATGTTTCTCTCGTCTTCCCGTTCGCTCGAG; 20N4, AATTCTCGAGCGAACGGGAAGACGAGAGAAACAT; 20N5, GCACGATCCCCAAAGTTAGAGACGT; 20N6, CTCTAACTTTGGGGATC; 20SEQ (kindly provided by P. Siliciano and C. Guthrie), AAAGGTAATGAGCCTCATTG; PTS, TAATACGACTCACTATAG. All oligonucleotides were purified by preparative acrylamide gel electrophoresis and their concentrations determined assuming $1 \mathrm{OD}_{260}=33 \mu \mathrm{g} / \mathrm{ml}$.

\section{Cloning and polymerase chain reaction}

A Sau3AI-AatII restriction fragment from the $S N R 20$ plasmid pES14 (kindly supplied by E. Shuster and C. Guthrie), and the oligonucleotides L20T, L20B, 20N1, 20N2, 20N3, and 20N4, were used to subclone the yeast U2 gene into PstI-EcoRI-cut pUC18 under the control of a T7 promoter and to place a unique $X h o I$ restriction site at the $3^{\prime}$ end of the gene (pT7U2). The internal deletion pT $7 \triangle B D$ was created by ligation of a purified 5 '-end PstI-BanI restriction fragment from pT7U2 with the oligonucleotides $20 \mathrm{N1}-20 \mathrm{~N} 6$ into PstI-EcoRI-cut pUC18. Except for the $5^{\prime}$ and $3^{\prime}$ termini of pT7 $\triangle \mathrm{BD}$, the sequence of this clone is identical to the sequence of $\triangle \mathrm{BD}$ described by Igel and Ares (1988). The branchpoint suppressor mutations, U36 and U37, were subcloned into the pT7U2 background from the plasmids p20-U36 and p20-U37, respectively (Parker et al. 1987) using standard cloning techniques. The complete or partial sequences of all clones were verified by dideoxy sequencing using the primers PTS, 20SEQ, or the M13 universal/reverse primers. The plasmid pT7 $\Delta 107$ contains the internal deletion, $\Delta 107$, originally isolated by Shuster and Guthrie (1988) and was kindly supplied by A. Zaug. Plasmids containing the HeLa cell and C. elegans $\mathrm{U} 2$ genes under the control of $\mathrm{T} 7$ promoters were kindly supplied by C. Pikielny and K. van Doren, respectively. The construction of the T7U1 clone will be described elsewhere. Polymerase chain reaction (PCR) was performed using AmpliTaq recombinant Thermus aquaticus DNA polymerase (Perkin-Elmer Cetus) according to the manufacturers instructions using either pT7 $\triangle \mathrm{BD}$ (see above) or YCp545-2 (kindly supplied by M. Ares) template DNAs, and the oligonucleotides L20T and 20N4. PCR-generated template DNAs were purified by phenol-chloroform extraction and ether extraction, followed by ethanol precipitation, and then used directly for in vitro transcription. In side-by-side comparisons, $\triangle B D$ RNAs prepared from both plasmid DNA templates and PCR-generated templates had identical activities in the reconstitution assay.

\section{Preparation of splicing extracts and RNAs}

Yeast whole-cell splicing extracts were prepared according to Lin et al. (1985) using the protease deficient yeast strain EJ101.

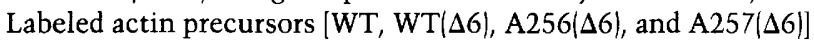
were synthesized in vitro using SP6 RNA polymerase as described by Lin et al. (1985), except the reactions contained 100 $\mu M$ cold UTP and $\left[\alpha^{32} \mathrm{P}\right] \mathrm{UTP}$ (Amersham) at $2 \mathrm{mCi} / \mathrm{ml}$. The specific activity of the labeled actin RNAs was $\sim 10,000 \mathrm{cpm} /$ fmole. Large-scale in vitro $T 7$ transcription reactions were performed using $50 \mathrm{~nm}$ template DNA in $40 \mathrm{~mm}$ Tris- $\mathrm{HCl} / \mathrm{pH} 8.0\}$, $15 \mathrm{mM} \mathrm{MgCl}_{2}, 2 \mathrm{~mm}$ spermidine, $10 \mathrm{~mm}$ dithiothreitol, $2.5 \mathrm{~mm}$ each ATP, CTP, GTP, UTP, 3 U/ $\mu 1$ T7 RNA polymerase (New England Biolabs) and were incubated at $37^{\circ} \mathrm{C}$ for $2 \mathrm{hr}$. $5^{\prime}$-Capped RNA was prepared identically, except the transcription reac-

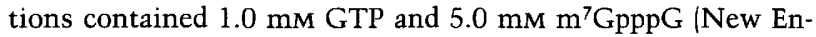
gland Biolabs). All RNAs synthesized in vitro were purified by preparative acrylamide gel electrophoresis and eluted overnight at $4^{\circ} \mathrm{C}$ in $0.5 \mathrm{M} \mathrm{NaOAc}(\mathrm{pH} 5.2), 1 \mathrm{mM}$ EDTA, $2.5 \%$ ( $\left.\mathrm{vol} / \mathrm{vol}\right)$ phenol-chloroform (1:1), followed by phenol-chloroform extraction, ether extraction, and ethanol precipitation. Purified RNAs were redissolved in water and their concentrations determined by absorption at $260 \mathrm{~nm}$, assuming $1 \mathrm{OD}_{260}=40$ $\mu \mathrm{g} / \mathrm{ml}$. Gel-purified rat (Novikoff Hepatoma) U2 RNA was kindly supplied by R. Reddy.

RNase H cleavage of the U2 RNA in splicing extracts and reconstitution of splicing activity

Oligonucleotide-mediated RNase $\mathrm{H}$ cleavage of the endogenous yeast U2 RNA in whole-cell splicing extracts was performed by incubating splicing extract $(50 \% \mathrm{vol} / \mathrm{vol})$ in $1 \times$ splicing buffer [60 mM potassium phosphate (pH 7.0), 3\% PEG 8000, 2 mM 
$\mathrm{MgCl}_{2}, 2 \mathrm{mM}$ spermidine, $2 \mathrm{mM} \mathrm{ATP}$ for $30 \mathrm{~min}$ at $30^{\circ} \mathrm{C}$ in the presence of oligonucleotide for in the absence of oligonucleotide in the control, mock-treated, reactions). The treated extracts were placed in ice water prior to their subsequent use in either Northern hybridization analysis, or in vitro reconstitution reactions. Reconstitution assays were performed by preincubation of $4.0 \mu$ l oligonucleotide-treated extract with $0.5 \mu$ l of in vitro synthesized RNA for $6 \mathrm{~min}$ at $23^{\circ} \mathrm{C}$. Splicing activity of there constituted mixtures was then assayed by the addition of $0.5 \mu \mathrm{l}$ of $2 \mathrm{nM}{ }^{32}$ P-labeled actin pre-mRNA $(20,000 \mathrm{cpm} / \mu \mathrm{l}$ in $2 \times$ splicing buffer) and the reactions (final volume, $5.0 \mu \mathrm{ll}$ incubated for $30 \mathrm{~min}$ at $23^{\circ} \mathrm{C}$. Splicing products were isolated as described by Lin et al. (1985) and run on $8 \%$ (29:1) acrylamide gels. For quantitation of splicing activity or RNA stability, gels were dried on $3 \mathrm{MM}$ paper and the appropriate bands excised and counted (Cherenkov). The fraction of pre-mRNA spliced was determined by the formula,

$$
\frac{\operatorname{cpm}_{\text {mRNA }} \theta}{\operatorname{cpm}_{\text {mRNA }} \theta+\operatorname{cpm}_{\text {pre-mRNA }}}
$$

where $\theta$ is equal to 2.2 and represents a factor that corrects for the difference in size of the mature mRNA in relation to the pre-mRNA.

\section{RNA analysis}

Northern hybridization analysis was performed using random primer extension probes generated from a pT7U2 DNA fragment as described in Cheng and Abelson (1987). 5' -End analysis of the U2 RNA fragment generated by RNase $\mathrm{H}$ cleavage was performed using primer extension as described in McPheeters et al. (1986). Modification of the T7D107 RNA during the reconstitution assay was performed by labeling T7 107 RNA with a mixture of all four $\left[\alpha^{32} \mathrm{P}\right] \mathrm{NTP}$ s to a specific activity of approximately $3300 \mathrm{cpm} / \mathrm{fmole}$ RNA. Then $20 \mathrm{~nm}{ }^{32} \mathrm{P}$-labeled T7 107 RNA was used in a standard reconstitution assay, both with and without splicing extract, performed with cold actin pre-mRNA substrate. At the end of the normal splicing assay, total RNA was recovered from the reaction, and modification of the RNA was assayed as described by Nishimura (1979). The extent of pseudouridine modification of the T7D107 RNA was calculated by comparison to both the total amount of labeled uridine $3^{\prime}$ monophosphate and guanosine $5^{\prime}, 3^{\prime}$ bis-phosphate released from the RNA in the analysis.

\section{Acknowledgments}

We would like to thank Jeff Sampson, Manny Ares, Stephany Ruby, Reinhard Rauhut, Michael Clark, and Lothar Krinke for critical reading of this manuscript. We would also like to thank Manny Ares, Claudio Pikielny, Ram Reddy, Stephany Ruby, Beth Shuster, Kevin van Doren, and Art Zaug for their advice and generous gifts of materials. This work was supported by Public Health Service grants GM12544 and GM32637 to D.S.M. and J.A., respectively. P.F. was supported by a grant from the Foundation Stiftelsen Blanceflor Boncompaqni-Ludovisi Född Bildt.

\section{References}

Adamiak, R.W. and P. Gornicki. 1985. Hypermodified nucleosides of tRNA: synthesis, chemistry, and structural features of biological interest. Prog. Nucleic Acid Res. and Mol. Biol. 32: 27-74.

Ares, M., Jr. 1986. U2 RNA from yeast is unexpectedly large and contains homology to vertebrate U4, U5, and U6 small nuclear RNAs. Cell 47: 49-59.
Ares, M., Jr., and A.H. Igel. 1989. Phylogenetic comparison of U2 small nuclear RNA sequences suggests a pseudoknotted structure. UCLA Symp. Mol. Cell. Biol. 94: 13-23.

Black, D.L., B. Chabot, and J.A. Steitz. 1985. U2 as well as U1 small nuclear ribonucleoproteins are involved in premessenger RNA splicing. Cell 42: 737-750.

Brow, D.A. and C. Guthrie. 1989. Splicing a spliceosomal RNA. Nature 337: 14-15.

Cech, T.R. 1986. The generality of self-splicing RNA: relationship to nuclear mRNA splicing. Cell 44: 207-210.

Cellini, A., R. Parker, J. McMahon, C. Guthrie, and J. Rossi. 1986. Activation of a cryptic TACTAAC box in the Saccharomyces cerevisiae actin intron. Mol. Cell. Biol. 6: 15711578.

Chabot, B., D.L. Black, D.M. LeMaster, and J.A. Steitz. 1985. The 3' splice site of pre-messenger RNA is recognized by a small nuclear ribonucleoprotein. Science 230: 1344-1349.

Chabot, B. and J.A. Steitz. 1987. Multiple interactions between the splicing substrate and small nuclear ribonucleoproteins in spliceosomes. Mol. Cell. Biol. 7: 281-293.

Cheng, S.-C. and J. Abelson. 1987. Spliceosome assembly in yeast. Genes Dev. 1: 1014-1027.

Domdey, H., B. Apostol, R.-J. Lin, A. Newman, E. Brody, and J. Abelson. 1984. Lariat structures are intermediates in yeast pre-mRNA splicing. Cell 39: 611-621.

Fabrizio, P., D.S. McPheeters, and J. Abelson. 1989. In vitro assembly of U6 snRNP: a functional assay. Genes Dev. 3: $2137-2150$.

Frendewey, D., A. Krämer, and W. Keller. 1987. Different small nuclear ribonucleoprotein particles are involved in different steps of splicing complex formation. Cold Spring Harbor Symp. Quant. Biol. 52: 287-298.

Guthrie, C. and B. Patterson. 1988. Spliceosomal snRNAs. Annu. Rev. Genet. 22: 387-419.

Hamm, J., M. Kazmaier, and I.W. Mattaj. 1987. In vitro assembly of Ul snRNPs. EMBO \%. 6: 3479-3485.

Hamm, J., V.L. van Santen, R.A. Spritz, I.W. Mattaj. 1989. Loop I of U1 small nuclear RNA is the only essential RNA sequence for binding of specific U1 small nuclear ribonucleoprotein particles. Mol. Cell. Biol. 8: 4787-4791.

Igel, A.H. and M. Ares, Jr. 1988. Internal sequences that distinguish yeast from metazoan U2 snRNA are unnecessary for pre-mRNA splicing. Nature 334: 450-453.

Keller, E.B. and W.A. Noon. 1985. Intron splicing: A conserved internal signal in introns of Drosophila pre-mRNAs. Nucleic Acids Res. 13: 4971-4981.

Kleinschmidt, A.M., J.R. Patton, and T. Pederson. 1989. U2 small nuclear RNP assembly in vitro. Nucleic Acids Res. 17: 4817-4828.

Krainer, A.R. and T. Maniatis. 1985. Multiple factors including the small nuclear ribonucleoproteins $U 1$ and $U 2$ are necessary for pre-mRNA splicing in vitro. Cell 42: 725-736.

Krämer, A., W. Keller, B. Appel, and R. Lührmann. 1984. The 5' terminus of the RNA moiety of Ul small nuclear ribonucleoprotein particle is required for the splicing of messenger RNA precursors. Cell 38: 299-307.

Kruger, K., P.J. Grabowski, A.J. Zaug, J. Sands, D.E. Gottschling, and T.R. Cech. 1982. Self splicing RNA: autoexcision and autocyclization of the ribosomal RNA intervening sequence of Tetrahymena. Cell 31: 147-157.

Langford, C.J., F.-J. Klinz, C. Donath, and D. Gallwitz. 1984. Point mutations identify the conserved, intron contained TACTAAC box as an essential splicing signal sequence in yeast. Cell 36: 645-653.

Legrain, P., B. Seraphin, and M. Rosbash. 1988. Early commitment of yeast pre-mRNA to the spliceosome pathway. Mol. Cell. Biol. 8: 3755-3760. 
Lin, R.-J., A.J. Newman, S.-C. Cheng, and J. Abelson. 1985. Yeast mRNA splicing in vitro. J. Biol. Chem. 260:1478014792.

Liautard, J.-P., J. Sri-Widada, C. Brunel, and P. Jeanteur. 1982. Structural organization of ribonucleoproteins containing small nuclear RNAs from HeLa cells. J. Mol. Biol. 162: 623643.

Lührmann, R. 1988. snRNP proteins. In Structure and function of major and minor small nuclear ribonucleoprotein particles (ed. M.L. Birnstiel), pp. 71-99. Springer-Verlag, Heidelberg.

Lutz-Reyermuth, C. and J.D. Keene. 1989. The U1 RNAbinding site of the U1 small nuclear ribonucleoprotein (snRNP)-associated Aprotein suggests a similarity with U2 snRNPs. Mol. Cell. Biol. 9: 2975-2982.

Mattaj, I.W. and E.M. De Robertis. 1985. Nuclear segregation of U2 snRNA requires binding of specific snRNP proteins. Cell 40: $111-118$.

Mattaj, I.W. 1986. Cap trimethylation of U snRNA is cytoplasmic and dependent on U snRNP protein binding. Cell 46: 905-911.

McPheeters, D.S., A. Christensen, E.T. Young, G. Stormo, and L.Gold. 1986. Translational regulation of expression of the bacteriophage T4 lysozyme gene. Nucleic Acids Res. 14: $5813-5826$.

Nishimura, S. 1979. Chromatographic mobilities of modified nucleotides. Cold Spring Harbor Monogr. Ser. 9A: 551-552.

Pan, Z.-Q. and C. Prives. 1988. Assembly of functional U1 and U2 human-amphibian hybrid snRNPs in Xenopus laevis oocytes. Science 241: 1328-1331.

Parker, R., P.G. Siliciano, and C. Guthrie. 1987. Recognition of the TACTAAC box during mRNA splicing in yeast involves base pairing to the U2-like snRNA. Cell 49: 229-239.

Patton, J.R., R.J. Patterson, and T. Pederson. 1987. Reconstitution of the Ul small nuclear ribonucleoprotein particle. Mol. Cell. Biol. 7: 4030-4037.

Patton, J.R. and T. Pederson. 1988. The $M_{\mathrm{r}} 70,000$ protein of the Ul small nuclear ribonucleoprotein particle binds to the 5 stem-loop of UI RNA and interacts with Sm domain proteins. Proc. Natl. Acad. Sci. 85: 747-751.

Pikielny, C.W., A. Bindereif, and M.R. Green. 1989. In vitro reconstitution of snRNPs: a reconstituted U4/U6 snRNP participates in splicing complex formation. Genes Dev. 3: 479487.

Reddy, R. and H. Busch. 1988. Small nuclear RNAs: RNA sequences, structure, and modifications. In Structure and function of major and minor small nuclear ribonucleoprotein particles. (ed. M.L. Birnstiel), pp. 1-37. Springer-Verlag, Heidelberg.

Reveillaud, I., M.-N. Lelay-Taha, J. Sri-Widada, C. Brunel, and P. Jeanteur. 1984. $\mathrm{Mg}^{2+}$ induces a sharp and reversible transition in $\mathrm{U} 1$ and $\mathrm{U} 2$ small nuclear ribonucleoprotein configurations. Mol. Cell. Biol. 4: 1890-1899.

Reyes, V.M. and J. Abelson. 1988. Substrate recognition and splice site determination in yeast tRNA splicing. Cell 55: $719-730$.

Riedel, N., S. Wolin, and C. Guthrie. 1987. A subset of yeast snRNA's contains functional binding sites for the highly conserved Sm Antigen. Science 235: 328-331.

Rodriguez, J.R., C.W. Pikielny, and M. Rosbash. 1984. In vivo characterization of yeast mRNA processing intermediates. Cell 39: 603-610.

Ruby, S.W. and J. Abelson. 1988. An early and hierarchic role of U1 small nuclear ribonucleoprotein in spliceosome assembly. Science 242: 1028-1035.

Shuster, E.O. and C. Guthrie. 1988. Two conserved domains of yeast U2 snRNA are seperated by 945 nonessential nucleotides. Cell 55: 41-48.

Steitz, J.A., D.L. Black, V. Gerke, K.A. Parker, A. Krämer, D Frendewey, and W. Keller. 1988. Functions of the abundant U-snRNPs. In Structure and function of major and minor small nuclear ribonucleoprotein particles, (ed. M.L. Birnstiel), pp. 115-154. Springer-Verlag, Heidelberg.

Tani, T. and Y. Ohshima. 1989. The gene for the U6 small nuclear RNA in fission yeast has an intron. Nature 337: 8790.

Wise, J.A., D. Tollervey, D. Maloney, H. Swerdlow, E.J. Dunn, and C. Guthrie. 1983. Yeast contains small nuclear RNAs encoded by single copy genes. Cell 35: 743-751.

Vijayraghavan, U., R. Parker, J. Tamm, Y. Iimura, J. Rossi, J. Abelson, and C. Guthrie. 1986. Mutations in conserved intron sequences affect multiple steps in the yeast splicing pathway, particularly assembly of the spliceosome. EMBO $J$. 5: $1683-1695$. 


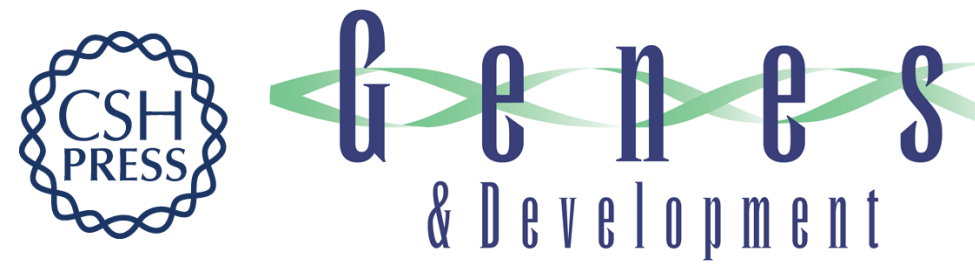

\section{In vitro reconstitution of functional yeast U2 snRNPs.}

D S McPheeters, P Fabrizio and J Abelson

Genes Dev. 1989, 3:

Access the most recent version at doi:10.1101/gad.3.12b.2124

References This article cites 45 articles, 16 of which can be accessed free at: http://genesdev.cshlp.org/content/3/12b/2124.full.htmI\#ref-list-1

License

Email Alerting

Receive free email alerts when new articles cite this article - sign up in the box at the top Service right corner of the article or click here.

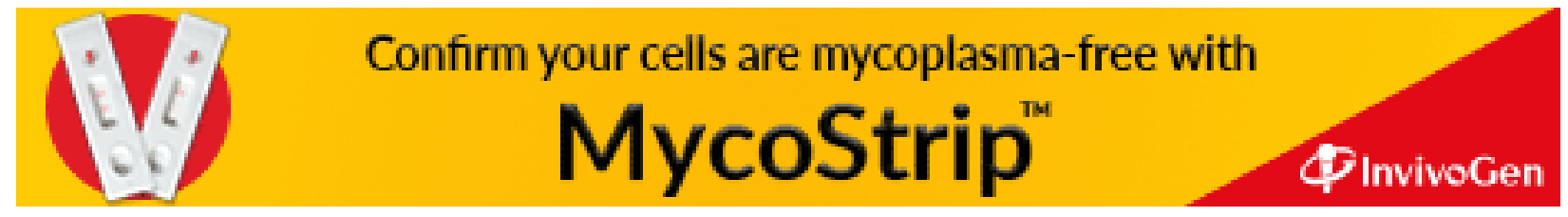

